\title{
ESTRUTURA FUNDIÁRIA VERSUS DEGRADAÇÃO DA VEGETAÇÃO: MUNICÍPIOS LINDEIROS DO BAIXO CURSO DO RIO IVAÍ-PR ${ }^{1}$
}

\author{
Structure land versus degration of vegetation: surrounding cities \\ in the lower course of the River Ivaí-PR \\ Estructura agraria versus el deterioro de la vegetación: \\ municipios linderos del curso inferior del Río Ivaí-PR
}

\begin{abstract}
Pedro Dias Mangolini Neves
Bacharel e Licenciatura Plena em Geografia pela Universidade Estadual de Maringá. Mestre em Geografia pela Universidade Estadual de Maringá. E.mail: pmangolini@hotmail.com
\end{abstract}

\section{Marta Luzia de Souza}

Doutora em Geociência e Meio Ambiente pela UNESP - Campus Rio Claro. Professora adjunta da Universidade Estadual de Maringá (UEM).E.mail:mlsouza@uem.br

\section{RESUMO}

Esta pesquisa parte do pressuposto de que a produção agropecuária é degradante quanto ao desmatamento da vegetação. Sendo assim, para tal investigação a pesquisa foi desenvolvida em municípios do entorno da planície aluvial do baixo curso do rio Ivaí, localizado na Mesorregião Noroeste Paranaense. Buscou-se entender se há relação entre as diferentes estruturas fundiárias encontradas na região (minifúndio, pequena, média e grande propriedade) com a degradação da vegetação. Para esta pesquisa foram aplicados questionário em 120 propriedades rurais analisadas em toda a área de estudo, em meados de 2011 e 2012 . Identificando-se assim, as formas de degradação do meio físico-natural advindas da vegetação, tais como, presença de APP (Área de Preservação Permanente) e Reserva Legal nas propriedades analisadas. Em síntese pode-se concluir que o minifúndio e as pequenas propriedades apresentam quase que total preservação da vegetação, já a média e a grande propriedade possuem menos de $40 \%$ das propriedades analisadas com APP e Reserva Legal. Isto se deve principalmente pelas pequenas propriedades e os minifúndios analisados serem em sua maioria assentamentos rurais, $\mathrm{o}$ que acarreta uma fiscalização do INCRA (Instituto Nacional de Colonização e Reforma Agrária) e que não ocorre nas médias e grandes propriedades.

Palavras-chave: propriedades rurais; Área de Preservação Permanente; Reserva Legal; Mesorregião Noroeste Paranaense

Esta pesquisa é parte de uma dissertação em Geografia do PGE/UEM(Programa de Pós- graduação em Geografia da Universidade Estadual de Maringá) que teve apoio financeiro e logístico da CAPES, CNPq (Processo CNPQ nº. 473023/2010-5) e do GEMA/UEM (Grupo de Pesquisas Multidisciplinares do Ambiente). 


\begin{abstract}
This research assumes that agricultural production is degrading as the deforestation of vegetation. Thus, for this research study was conducted in municipalities around the floodplain of the lower course of the river Ivaí, located in Northwest of Parana Mesoregion. We sought to understand whether there is a relationship between different land structures found in the region (small farms, small, medium and large property) with vegetation degradation. For this research a questionnaire was applied in 120 farms analyzed throughout the study area in mid-2011 and 2012. Identifying thus forms of degradation arising from the physical and natural vegetation, such as the presence of APP (Permanent Preservation Area) and Legal Reserves in the properties analyzed. In summary it can be concluded that the small farms and small farms have almost complete preservation of vegetation as the average and large property they own less than $40 \%$ of the properties analyzed APP and Legal Reserves. This is mainly by small farms and smallholdings analyzed are mostly rural settlements, which carries a surveillance INCRA (National Institute of Colonization and Agrarian Reform) and does not occur in medium and large properties.
\end{abstract}

Keywords: rural property; Permanent Preservation Area; Legal Reserve; Northwest of Parana Mesoregion

\title{
RESUMEN
}

Esta investigación supone que la producción de la actividad agropecuaria es degradante respecto a la deforestación de la vegetación. Por lo tanto, ella se llevó a cabo en los municipios alrededor de la llanura aluvial del curso inferior del río Ivaí, ubicado en la Mesorregión del Noroeste Paranaense. Hemos tratado de entender si existe una relación entre las diferentes estructuras agrarias que se encuentran en la región (minifundio, pequeña, mediana y grande propiedade) con la degradación de la vegetación. Para esta investigación se aplicó un cuestionario en 120 propiedades rurales analizadas en todo el área del estudio, a mediados de 2011 y 2012, identificando asílas formas de degradación del medio físico y natural que vienen de la vegetación, tales como la presencia de APP (Área de Preservación Permanente) y Reservas Legales en las propiedades analizadas. En resumen, se puede concluir que los minifundios y las pequeñas propiedades conservan su vegetación casi completamente, mientras que menos del $40 \%$ de las propiedades medianas y grandes analizadas poseen APP y Reserva Legal. Esto ocurre gracias, especialmente, al hecho de que los minifundios y las pequeñas propiedades analizadas son en su mayoría los asentamientos rurales, lo que implica la fiscalización del INCRA (Instituto Nacional de Colonización y Reforma Agraria), lo que no sucede en las medianas y grandes propiedades.

Palabra clave: propiedade rurales; Área de Preservación Permanente; Reserva Legal; Mesorregión del Noroeste Paranaense 


\section{INTRODUÇÃO}

A degradação do meio físico-natural em municípios brasileiros está cada vez mais presente em nossos cernes, que podem ter suas causas associadas a fenômenos naturais e antrópicos, como é o caso das práticas da agricultura e da pecuária que ao desmatarem áreas para suas atividades de uso, fazem com que o solo perca milhares de nutrientes por ano.

Essa terra perdida, dependendo da profundidade e do tipo de solo, pode tornar o solo improdutivo. As camadas superiores são onde estão os nutrientes que são removidos e carreados para outras áreas. O material erodido que foi carreado se fixará em outras áreas prejudicando a qualidade do solo em determinado local; ou seja, um prejuízo nutricional e consequentemente financeiro na área erodida e na área de deposição. O solo advindo das erosões também pode ser transportado até cursos d'água, assoreando os leitos dos rios e afetando toda a região marginal.

Existem várias pesquisas voltadas à degradação da vegetação em áreas rurais, no entanto, o levantamento da degradação da Reserva Legal e Áreas de Preservação Permanente com a estrutura fundiária, ou seja, se o tamanho da propriedade é determinante para a presença de algum tipo de degradação ambiental, é ainda incipiente nas pesquisas brasileiras.

Sendo assim, o principal objetivo desta pesquisa foi analisar as implicações ambientais em municípios do baixo curso do rio Ivaí-PR, no período de 2010 a 2012, realizando o levantamento em 120 propriedades rurais, verificando os diferentes tipos de propriedades rurais e suas relações com a vegetação local, como a Área de Preservação Permanente e a Reserva Legal.

A presente pesquisa se justifica pela temática atual e necessária que reúne questões agrárias e ambientais em uma área que foi e é palco da implementação da reforma agrária brasileira, pois quando se observa a ocupação do espaço agrário brasileiro, desde o período colonial até os dias de hoje, supõe-se que a preservação do meio ambiente é incompatível com a obtenção de lucro tanto pela pequena propriedade quanto pelas atividades de agronegócio desenvolvidas na grande propriedade.

A hipótese desta pesquisa parte da premissa de que a busca para uma maior produtividade da grande propriedade acabe motivando um desinteresse pelas questões ambientais e o pequeno proprietário vise preservar o ambiente de sua propriedade em busca de sua sobrevivência e de uma maior produtividade. 


\section{ESTRUTURA FUNDIÁRIA E DEGRADAÇÃO DA VEGETAÇÃO NAS PROPRIEDADES RURAIS DO NOROESTE DO PARANÁ}

Para a explanação sobre a estrutura fundiária na área de estudo foi realizado primeiramente um resgate histórico do tema no território brasileiro.

O Brasil tem sua estrutura agrária ligada a um histórico de concentração de terras por parte de uma elite que começa desde a colonização pelos portugueses, primeiramente na forma das capitanias hereditárias, como descreve Carvalho (2008):

as capitanias hereditárias eram estruturas jurídicas, políticas, administrativas, econômicas, e
não simplesmente latifúndios (grandes extensões de terras). Eram indivisíveis, inalienáveis e
transmitidos hereditariamente. Foram concedidos pelo Rei através de Cartas Régias que de-
finiam as condições de sua posse e governo. O donatário era proprietário de direito, de fato
e hereditário; deveria povoá-la e desenvolve-la à sua custa e risco. A posse hereditária era a
forma de garantir aos hereditários dos donatários os mesmos direitos à sua posse e governo.

E em seguida pelas sesmarias como Andrade (2002, p. 13) descreve:

o processo de colonização deu origem a sistemas de apropriação da terra onde ela era dividida em grandes lotes - as sesmarias - que eram dadas a pessoas que dispunham de recursos para explorá-las, utilizando a força de trabalho, sob coação - indígenas e negros africanos; este sistema permitiu a formação de grandes latifúndios e a exploração das terras em função de uma economia de exportação. Só em 1822, graças à visão política de José Bonifácio de Andrada e Silva, o sistema das sesmarias foi extinto e substituído pelo direito de posse, cabendo ao posseiro requerer a propriedade da terra que ocupava. Procurava-se, desse modo, democratizar o acesso à propriedade da terra, embora dificilmente os posseiros tivessem condições de legalizar os lotes de que dispunham, devido à cobiça dos grandes proprietários e dos altos dignitários governamentais. Nos meados do século XIX, visando consolidar o poder dos proprietários e abrir perspectivas aos colonos estrangeiros que eram atraídos para o Brasil, estabeleceu-se o acesso a terra através do contrato de compra e venda, consolidando-se o poder dos latifundiários.

Estas políticas adotadas pelo governo e o modo como foi realizada a colonização brasileira foram responsáveis pela desigualdade fundiária no Brasil. Em particular, são destacados os efeitos do crédito rural subsidiado, uma das principais políticas voltadas para modernização da agricultura brasileira.

Segundo Martine e Beskow (1987), o crédito rural foi desigualmente distribuído entre regiões, entre tipos de produtos e entre classes de tamanho de produtores. Outras políticas, como os preços mínimos, o seguro rural e as políticas de subsídios, além de programas especiais de desenvolvimento regional, também atuaram no sentido de incentivar a concentração fundiária, além de beneficiar atividades e regiões específicas e favorecer a grande produção.

Graziano da Silva (1980) ressalta que, em virtude dos avanços das transformações capitalistas na agricultura e em resultado de políticas governamentais favorecendo as pro- 
priedades de grande porte e acarretando atraso nos pequenos estabelecimentos, a propriedade da terra tem-se tornado cada vez mais concentrada, com latifúndios ocupando cada vez mais áreas, e consequentemente, os minifúndios perdendo cada vez mais terra.

Já quanto à legislação federal, o minifúndio é o imóvel rural de área e possibilidades menores às da propriedade familiar, conforme está expresso no art. $4^{\circ}$, inciso IV do Estatuto da Terra (BRASIL, 1964).

A Constituição Federal Brasileira vigente, em seu art. 185 (BRASIL, 1988), instituiu a "Pequena Propriedade" e a "Média Propriedade", considerando-as insuscetíveis desapropriação por interesse social para fins de reforma agrária, mas as suas definições foram remetidas para a lei ordinária, o que veio a acontecer, com relativo atraso, através da Lei no 8.629 (BRASIL, 1993).

Por essa lei, em seu art. $4^{\circ}$, inciso II, alínea $a$, a "Pequena Propriedade" foi definida como o imóvel rural de área compreendida entre 1 (um) a 4 (quatro) módulos fiscais.

A definição da mesma não ficou harmonizada com o inciso XXVI do art. $5^{\circ}$ da Constituição Federal (BRASIL, 1988), assim expresso:

XXVI - a pequena propriedade rural, assim definida em lei, desde que trabalhada em família, não será objeto de penhora para pagamento de débitos decorrentes de sua atividade produtiva, dispondo a lei sobre os meios de financiar o seu desenvolvimento.

Nesta pesquisa algumas pequenas propriedades (propriedades) e minifúndios (propriedades) se apresentavam como assentamentos rurais, que segundo Bergamasco e Norder (1996), podem ser definidos como a criação de novas unidades (independentes entre si ou não) de produção agrícola, por meio de políticas governamentais, visando o reordenamento do uso da terra; ou a busca de novos padrões sociais na organização do processo de produção agrícola: projetos de colonização; reassentamento de populações atingidas por barragens; planos estaduais de valorização das terras públicas e de regularização possessória; programas de reforma agrária; e criação de reservas extrativistas.

A “Média Propriedade" foi também definida pela Lei no 8.629 (BRASIL, 1993), resumindo-a à dimensão superior de 4 (quatro) até 15 (quinze) módulos fiscais. Originariamente, também havia o componente familiar embutido em sua definição aprovada no Congresso Nacional (alínea $b$ ) como na definição da "Pequena Propriedade", mas o Presidente da República vetou essa parte, argumentando dessa vez, de que haveria discriminação à propriedade em condomínio, por cooperativas e associações, bem como nos casos de arrendamento e de parcerias e outras formas de posse da terra (MARQUES, 2011, p. 60). 
Os incisos II e III do art. $4^{\circ}$ da Lei no 8.629 (BRASIL, 1993), conceituam apenas as pequenas e médias propriedades, portanto, os imóveis com área total superior há 15 (quinze) módulos fiscais foram classificadas como "Grande Propriedade".

A área de estudo é o reflexo do que ocorre em vários estados do Brasil em relação às múltiplas estruturas fundiárias encontradas, ou seja, na grande quantidade de minifúndios e pequenas propriedades, e na baixa quantidade de latifúndios e grandes propriedades, porém a área ocupada por estes diversos tipos de estruturas fundiárias não estão de acordo com sua quantidade. Ou seja, os poucos latifúndios e grandes propriedades ocupam uma área superior à ocupada pela grande quantidade de minifúndios e pequenas propriedades, no Brasil e na área de estudo desta pesquisa.

\section{DEGRADAÇÃO DA VEGETAÇÃO}

A agricultura e a pecuária são atividades que geram impactos ao meio ambiente, seja em grande ou pequena escala, isso dependerá das técnicas e práticas que forem utilizadas. Tendo em vista que para a maximização do lucro, os produtores, a fim de obter novas áreas agricultáveis retiram a vegetação nativa.

O desenvolvimento contínuo dessas práticas, de retirada de solos férteis sem a reposição de nutrientes, acarreta na perda da fertilidade da terra. Levando em consideração o tipo de solo da região, isso pode intensificar os processos de degradação do bioma.

A vegetação é de extrema importância para a manutenção da biodiversidade e proteção dos solos, que além de realizar a fotossíntese, atua na proteção do solo, pela capacidade de interceptar as chuvas, diminuindo a incidência direta sobre os solos e interrompendo assim o deslocamento mais expressivo de sedimentos, minimizando seu efeito erosivo.

Para Tricart (1977) as modificações na cobertura vegetal, provocam alterações no equilíbrio do ambiente, onde essas modificações aceleram os processos de erosão, aumento da temperatura local, redução da recarga d'água de rios e aquíferos, entre outros eventos, justificando-se assim a manutenção da cobertura vegetal para o equilíbrio ambiental.

Como forma de diminuir o desmatamento de todas as florestas brasileiras em 15 de setembro de 1965 foi criada a Lei n. 4.771 (BRASIL, 1965), que institui o novo Código Florestal para proteger as APP's, Áreas de Preservação Permanente, que tem a função ambiental de preservar os recursos hídricos, a paisagem, a estabilidade geológica, a biodiversidade, o fluxo gênico de fauna e flora, proteger o solo e assegurar o bem-estar das populações humanas. Assim como, para proteger também a Reserva Legal. 
Conforme descrito nos conceitos a Reserva Legal é a área localizada no interior de uma propriedade ou posse rural, ressalva a de preservação permanente, representativa do ambiente natural da região e necessária ao uso sustentável dos recursos naturais, à conservação e reabilitação dos processos ecológicos, à conservação da biodiversidade e ao abrigo e proteção da fauna e flora nativas (BRASIL, 1965).

Destaca-se novamente que a Área de Preservação Permanente pode, às vezes, ser confundida com a Reserva Legal, porém elas são distintas. Na Reserva Legal é permitida a exploração econômica de forma sustentável, já a Área de Preservação Permanente constituem áreas protegidas, onde não se permite a atividade de exploração econômica.

\section{CARACTERIZAÇÃO GEOGRÁFICA DA ÁREA}

A área de estudo pertence à Mesorregião Noroeste do estado do Paraná e compreende alguns municípios, Tapira, Douradina, Ivaté, Icaraíma, Querência do Norte e Santa Mônica, que estão localizados no entorno da planície aluvial que compõem parte do baixo curso do rio Ivaí, Paraná (Figura 1).

A pesquisa inicialmente contemplava 8 municípios, de acordo com o trajeto percorrido durante a aplicação dos questionários, seguindo de Santa Mônica para Tapira, depois Douradina, Ivaté, Icaraíma e Querência do Norte, Santa Cruz de Monte Castelo e Santa Isabel do Ivaí foram os últimos municípios programados para aplicação do questionário, porém todos os produtores questionados (minifúndio, pequena, média e grande propriedade) já tinham conhecimento desta pesquisa e se negaram a responder o questionário, sendo assim a pesquisa restringiu-se a seis municípios.

Este trecho abrange cerca de $150 \mathrm{~km}$ de comprimento do rio Ivaí, e toda a área de estudo possui $3.115,087 \mathrm{~km}^{2}$ (IBGE, 2002). 


\section{Figura 1: Mapa de localização da área de estudo}
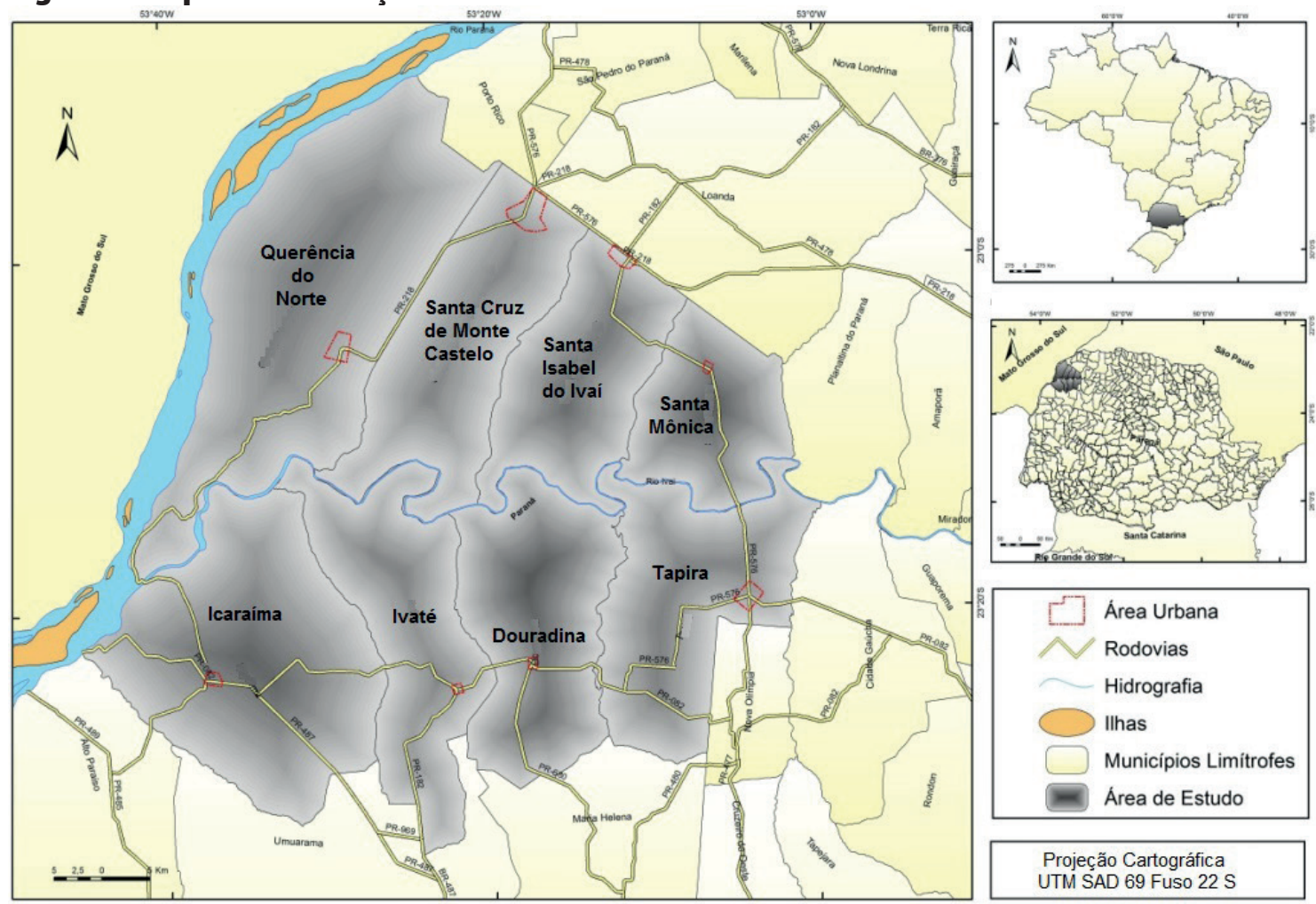

7 Área Urbana

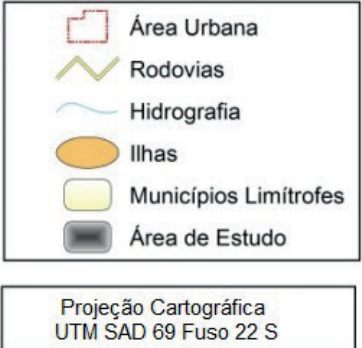

Fonte: Base Cartográfica ITCG (2002); IBGE (2010)

Elaborador: Neves (2013)

Segundo IPARDES (2012a), Querência do Norte e Santa Mônica estão inseridas na Microrregião Geográfica de Paranavaí, e os municípios de Douradina, Icaraíma, Ivaté e Tapira estão inseridos na Microrregião Geográfica Umuarama, sendo que estas duas Microrregiões estão inseridas na Mesorregião Geográfica Noroeste Paranaense (Figura 2).

A Microrregião Geográfica de Umuarama possui uma área territorial de 10.397,677km² e uma população de 265.092 habitantes em 2010. A produção agropecuária se baseia na mandioca, soja e cana de açúcar, com uma produção em toneladas de, respectivamente, 742.743; 331.658; 5.726.538; sua produção bovina é de 945.139 cabeças de gado (IPARDES, 2012d).

Já a Microrregião Geográfica de Paranavaí possui uma área e população semelhante à Microrregião Geográfica de Umuarama, com 10.280,484km² e 270.794 habitantes, também em 2010. A cana de açúcar aparece como a cultura mais produtiva desta microrregião, com 9.581.875 toneladas em 2010, seguido da mandioca com 998.666 toneladas, e a laranja com 263.559 toneladas também em 2010. A Microrregião Geográfica de Paranavaí possui 961.819 cabeças de gado bovino (IPARDES, 2012c). 


\section{Figura 2: Mesorregião Geográfica Noroeste Paranaense dividida em suas microrregiões}

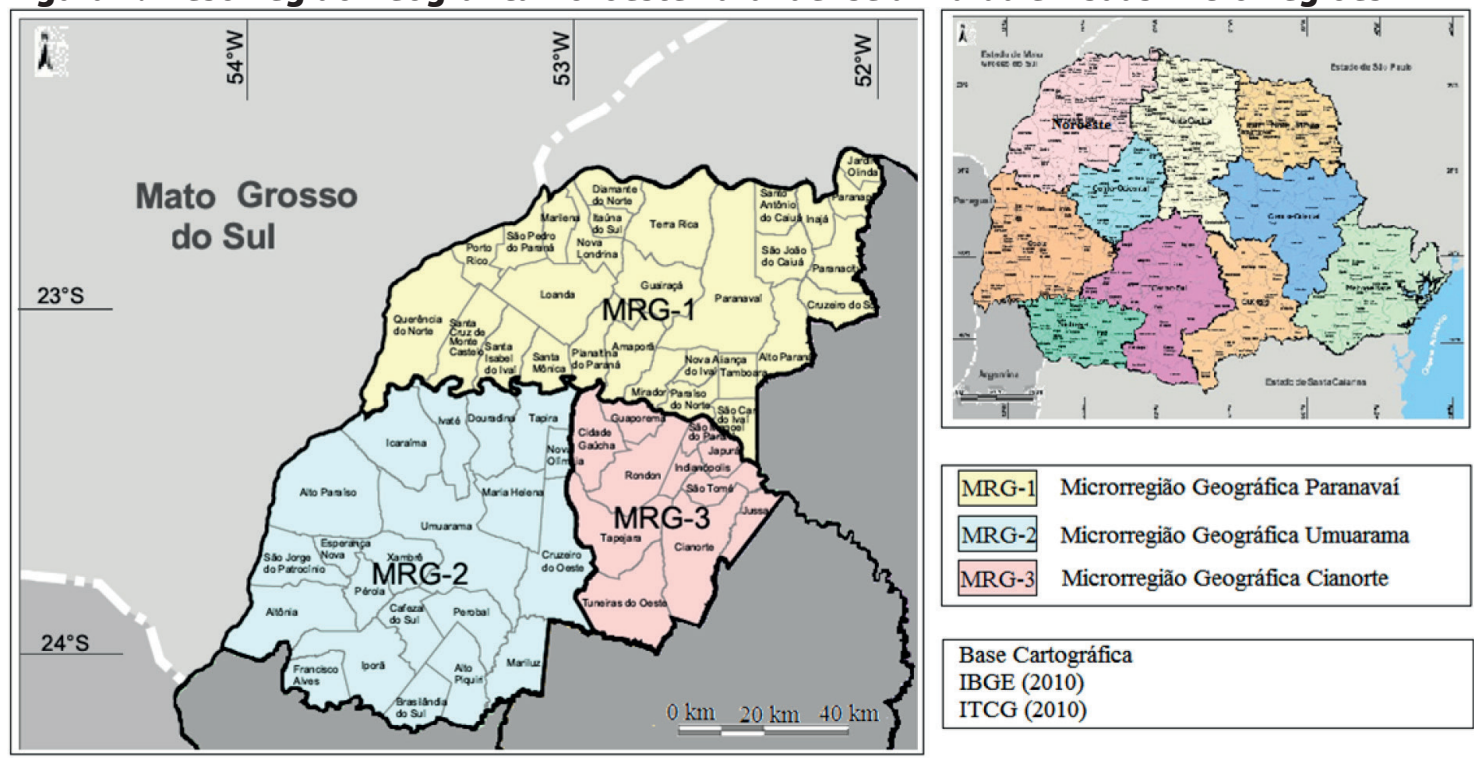

Adaptado por: Neves (2013)

A Mesorregião Geográfica Noroeste Paranaense possui uma área de 24.750,384km² e uma população de 678.319 habitantes, em 2010. Sua maior produção em 2010 foi de cana de açúcar com 21.899.995 toneladas, seguida da mandioca com 2.055.524 toneladas e da soja com 548.173 toneladas. E a produção de gado bovino é de 2.160 .877 cabeças (IPARDES, 2012b).

Como pôde ser observado, a área de estudo está inserida numa região com baixa densidade populacional, e consideravelmente nova, baseando-se pela colonização recente da região e fundação dos municípios a partir da década de 1950.

Segundo a carta climática do estado do Paraná realizada pelo Instituto Agronômico do Paraná - IAPAR (1994), a classificação climática regional baseada em Köppen (1948) é o tipo Cfa, ou seja, clima Subtropical Úmido Mesotérmico, com meses de verão quentes e geadas menos frequentes. Considerando se que ao norte do paralelo $24 \mathrm{~S}$, há uma tendência de concentração das chuvas nos meses de verão, sem estação seca definida (DERPESCH et al, 1991, p. 27).

O substrato rochoso da área de estudo pertence à Formação Caiuá, é constituído por areia quartzosa das frações médias, fina a muito fina predominantemente, e friável, maciço ou com estratificação cruzada de grande porte, apresentando susceptibilidade a processos erosivos. Conforme estudos de Gasparetto e Souza (2003). A Formação Caiuá assenta-se de forma discordante sobre os basaltos da Formação Serra Geral e está, segundo alguns autores, recoberta por uma espessa cobertura pedológica de origem do próprio arenito. 
Os solos da região, embora sejam formados pelo mesmo material de origem (arenitos), variam bastante em sua composição, fazendo, dessa forma, com que sejam encontradas várias classes em campo.

A partir dos mesmos estudos de Gasparetto e Souza (2003) foi considerado que a cobertura pedológica encontrada sobre os arenitos da Formação Caiuá, possuí uma textura areno-argilosa, de composição predominantemente arenosa com silte e argila, com ou sem a presença de cascalhos na base. Os materiais que compõem essa cobertura, porém, às vezes, são semelhantes às rochas sotopostas, ou mesmo alterações destas, dificultando a separação litológica das rochas.

O relevo da região apresenta-se como plano na maior parte de sua extensão, sendo também remetido à classe suavemente ondulado em poucos trechos distintos, segundo a classificação de Maack (1981).

O curso inferior do rio Ivaí, possui 150km de comprimento entre altitudes de 250 a $230 \mathrm{~m}$ de altitude, que se estende do início da planície à sua foz no rio Paraná. Neste segmento o rio Ivaí passa a escoar sobre os arenitos da Formação Caiuá e dos sedimentos aluvionares da planície. O desnível neste trecho é de apenas 20m, e a declividade é de aproximadamente $0,01 \%$, mostrando que o rio Ivaí corre pela topografia mais suave da bacia, compreendendo um relevo de colinas bastante suaves, ao longo do qual seu curso está praticamente desprovido de cachoeiras. Tais informações foram constatadas na investigação realizada por Destefani (2005, p. 24) em sua dissertação.

A vegetação da área de estudo é uma mescla de mata pluvial subtropical com áreas de pastoreio e de plantações que, segundo o IBGE (1992), são de Floresta Estacional Semidecidual, um tipo de vegetação condicionada a uma dupla estacionalidade climática, uma tropical com verões chuvosos, seguida por estiagem acentuada e outra subtropical sem período seco, mas com seca fisiológica provocada pelo frio no inverno, com temperaturas médias inferiores a $15^{\circ} \mathrm{C}$ no período mais frio, o que ocasiona na vegetação a perda das folhas (20\% a 50\%) nos períodos desfavoráveis.

Autores como Bigarella e Mazuchowski (1985) e Troppmair (1994) descreveram que a Região Noroeste Paranaense era totalmente recoberta por uma vegetação do tipo mata pluvial tropical, principalmente ao longo das drenagens, apresentava-se sempre densa e formada por árvores que chegavam a 40 metros de altura, dentre as quais se destacavam: peroba-rosa, sapuva, guarita, cana fístula, e várias espécies de menor porte. 
Durante o processo de colonização, os ciclos de exploração determinados pelas atividades econômicas, marcaram diversas fases da ocupação do território e fizeram com que as florestas e domínios naturais fossem substituídos inicialmente pela cultura do café, por volta da década de 1940. Na região deste estudo, a cobertura vegetal é composta predominantemente por algumas culturas como arroz, soja, milho, mandioca e cana de açúcar e também por pastagem, incluindo a Área de Preservação Permanente e a Reserva Legal.

Se baseando em aspectos socioeconômicos, a partir de estudos realizados por Haracenko (2002, p. 44) podemos entender que a ocupação européia da Região Noroeste do estado do Paraná se dá a partir do século XVI, com o português Aleixo Garcia. A segunda fase desta ocupação é comandada pela entrada do capital, em que as terras do Estado, através de projetos de colonização privados, passam a pertencer a uma empresa colonizadora, a qual realizava a venda de pequenos lotes para pequenos agricultores, o que se caracteriza como uma reocupação por colonização.

Completando o raciocínio a partir de estudos de Campos (1999), podemos observar que no início da segunda metade do século XIX os imigrantes europeus passaram a ocupar o interior do estado e realizar a derrubada da mata para sua subsistência desencadeando um processo de exploração madeireira e o aumento vertiginoso do número de serrarias. Esta abundante exploração da vegetação primária promoveu grandes expansões de espaços abertos, e conforme se deu o desaparecimento da mata, as mesmas terras foram sendo ocupadas inicialmente pela cultura cafeeira, que dominou a economia da região até o início da década de 1970.

É bom frisarmos que, segundo Moro (1991), o declínio da cultura do café promoveu e solidificou o processo de substituição de culturas cedendo espaço para a cultura associada da soja e do trigo e para as pastagens. A introdução gradativa nos últimos 30 anos e a grande ascensão entre os anos de 1970 a 1985 dessas culturas comerciais foram acompanhadas e promovidas pelo processo de modernização da agricultura paranaense.

$\mathrm{Na}$ área de estudo desta pesquisa houve um grande conflito por terras nas décadas de 1990 e 2000, proporcionando a criação de alguns assentamentos na região. Cinco destes assentamentos tiveram propriedades analisadas na presente pesquisa, concomitantemente com outras propriedades maiores. Tais assentamentos foram o Ribeirinha (Icaraíma-PR, com 522,41 ha e abriga 21 famílias), o Zarantonello (Icaraíma-PR, com 359,4 hectares e 17 famílias), Pontal do Tigre (Querência do Norte-PR, com 8.096,10ha e 336 famílias assentadas), Che Guevara (Querência do Norte-PR, possuí 2.453,20ha e 70 famílias) e o Ildo Luiz Peruzzo (Santa Mônica, com 1256ha, e 37 famílias assentadas). 


\section{MATERIAL E MÉTODOS}

Para o desenvolvimento desta pesquisa e para lograr seus objetivos foi utilizada como procedimento metodológico a análise descritiva e indutiva.

Nesta pesquisa a análise descritiva foi aplicada em cada propriedade rural analisada, destacada nos pontos do questionário, referentes a estrutura fundiária de cada propriedade até sua condição ambiental.

As propriedades analisadas são uma amostragem, pois como na área de estudo existem muitas propriedades, para realizar a aplicação dos questionários em todas elas acabaria deixando a pesquisa inviável. Por exemplo, nesta pesquisa foram analisadas 120 propriedades como amostragem de 5.865 propriedades localizadas na área de estudo.

O método indutivo parte do particular, a partir da observação dos fenômenos concretos da realidade e das relações existentes entre eles, para se chegar à generalização. Utilizando constatações particulares, chega-se a uma verdade geral, a partir de aplicação de questionário e/ou entrevistas; propostos pelos empiristas, Francis Bacon, Thomas Hobbes, John Locke e David Hume (apud FREITAS, 2012).

Neste caso, as constatações particulares são as análises realizadas nas propriedades, já a generalização (verdade geral), seria a empregada em todas as propriedades da área de estudo, porém se torna inviável quando a população pesquisada possui um número elevado.

Nesta pesquisa, as informações descritivas foram adquiridas através do questionário fechado, já as informações indutivas foram colhidas no decorrer da aplicação do questionário com o diálogo entre pesquisador e questionado ao mesmo tempo em que o questionário era aplicado. Tais informações puderam explicar, por exemplo, como se dá a preservação da vegetação.

O procedimento prático desta pesquisa foi realizado em duas etapas: o campo e o laboratório. A etapa do campo se realizou com as visitas à área de estudo para reconhecimento e a aplicação dos questionários, e a etapa do laboratório, se fez antes do campo e posteriormente a ele.

O trabalho de campo constitui parte de um experimento científico, uma atividade realizada no local onde o objeto de estudo ocorre naturalmente, engloba coleta e o registro de dados.

O trabalho de campo foi realizado em duas fases, a primeira foi realizada no $2^{\circ}$ semestre de 2011 para reconhecimento da área e um primeiro contato com algumas propriedades e assentamentos da área pesquisada. A segunda fase foi realizada no início do $1^{\circ} \mathrm{se}-$ mestre de 2012 para obtenção de dados com coordenadas geográficas por meio do Global 
Positioning System (GPS), registros fotográficos e a aplicação dos questionários nas propriedades selecionadas.

Para a determinação do tamanho de amostra, o pesquisador precisa especificar o erro amostral tolerável, ou seja, o quanto ele admite errar na avaliação dos parâmetros de interesse.

Barbetta (1998, p. 58) apresenta uma fórmula para o cálculo do tamanho mínimo da amostra da pesquisa, em que:

$\mathrm{N}$ - tamanho (número de elementos) da população;

$\mathrm{n}$ - tamanho (número de elementos) da amostra;

n1 - uma primeira aproximação para o tamanho da amostra;

E - erro amostral tolerável.

Um primeiro cálculo do tamanho da amostra pode ser feito, mesmo sem conhecer o tamanho da população, a partir da seguinte expressão:

$$
\mathrm{n}_{1}=\frac{1}{\mathrm{E}^{2}}
$$

Conhecendo o tamanho $\mathrm{N}$ da população, podemos corrigir o cálculo anterior, por:

$$
\mathrm{n}=\frac{\mathrm{N} \cdot \mathrm{n}_{1}}{\mathrm{~N}+\mathrm{n}_{1}}
$$

Para esta pesquisa foi utilizado um erro amostral de 9\%, para um número de 5.865 propriedades, e de acordo com a fórmula para determinar o tamanho da amostra foi realizado um questionário em 120 propriedades distribuídas na região de estudo.

O erro amostral de $9 \%$ foi decidido por ser o erro amostral limite para uma amostragem segundo Barbetta (1998, p. 59) e possibilitar uma pesquisa com 120 propriedades, lembrando que a área é extensa e está inserida em seis municípios e as propriedades possuem vias, em geral, de difícil acesso.

O IBGE possui a quantidade de propriedades por município, porém eles não estão divididos (na área de estudo) por tipo de propriedade (minifúndio, pequena, média e grande propriedade) e sim por área em hectare, dividida entre quatro divisões, menos de 10ha; de 10 ha a 100 ha; de 100 ha a 1.000 ha; e mais do que 1.000 ha.

Com esta divisão não se pode identificar o número total de cada tipo de propriedade nos municípios estudados, somente é possível ter uma ideia de que há mais minifúndios, seguido de grandes e médias propriedades. 
Os documentos cartográficos foram elaborados no software ArcGIS 10, o sistema de projeção utilizado foi o UTM (Universal Transversal de Mercator) e datum horizontal SAD 69. Sendo que o processo no qual esteve envolvido a elaboração dos documentos cartográficos foi inicialmente marcado pelo georreferenciamento das cartas topográficas utilizadas como base para seu desenvolvimento, em seguida foram delimitados os municípios da área de estudo, com as vias de acessos pertencentes à região.

A tabulação dos questionários proporcionou a elaboração e a combinação de tabelas de dados da estrutura fundiária com dados de presença de feições erosivas, APP, Reserva Legal e de aplicação de agrotóxicos, proporcionando ao final desta pesquisa a elaboração de gráficos que deixaram mais nítido o resultado final. Esta tabulação foi realizada a partir do software Sphinx Léxica - V5, adquirido pelo grupo de pesquisa NEMO - Núcleo de Estudos de Mobilidade e de Mobilização da Universidade Estadual de Maringá.

\section{RESULTADOS E DISCUSSÃO}

Analisando o tamanho das propriedades rurais que foi aplicado o questionário no decorrer desta pesquisa, pode-se perceber pela tabela 1, que há certa predominância dos minifúndios e certa paridade entre as pequenas, médias e grandes propriedades.

Tabela 1: Tamanho das propriedades analisadas

\begin{tabular}{|l|l|l|l|}
\hline Tamanho da propriedade & Módulos fiscais & Propriedades & Porcentagem (\%)
\end{tabular}

\begin{tabular}{cccc} 
Grande propriedade & $>15$ & 23 & 19,2 \\
\hline Média propriedade & 4 a 15 & 23 & 19,2 \\
\hline Pequena propriedade & 1 a 4 & 14 & 11,7 \\
\hline Minifúndio & $<1$ & 60 & 50 \\
\hline
\end{tabular}

Fonte: Neves (2013)

No minifúndio, que são propriedades menores que um módulo fiscal, foi aplicado questionário em 60 propriedades (50\%). Na pequena propriedade, foram 14 propriedades $(11,7 \%)$, propriedades que tinham de 1 a 4 módulos fiscais. Já na média propriedade, que são propriedades de 4 a 15 módulos fiscais, foram questionadas 23 propriedades (19,2\%), sendo idêntico ao número de grandes propriedades que foram questionadas, isto é, propriedades com mais do que 15 módulos fiscais.

Lembrando que o tamanho do módulo fiscal é diferente para cada município, ele segue uma relação do desenvolvimento de cada município, e é definido pelo decreto $n^{\circ} .84 .685$ (BRASIL, 1980).

a 
Querência do Norte possui o maior módulo fiscal da área estudada, 30 hectares, Santa Cruz de Monte Castelo, Santa Isabel do Ivaí, Santa Mônica e Tapira possuem mesmo tamanho de módulo fiscal, 24 hectares. Em Douradina o módulo fiscal corresponde a 22 hectares; em Icaraíma é de 22 hectares também; já em Ivaté é menor, 1 módulo fiscal corresponde a 20 hectares.

Em oitenta e sete das propriedades analisadas, ou seja, em 72,50\% dos questionários a APP está presente, e a lei no 4.771/65 (BRASIL, 1965) não se cumpre em trinta e três $(27,50 \%)$ das propriedades rurais analisadas.

Em alguns locais, como no assentamento Che Guevara, a APP (Figura 14) está preservada, ou seja, a vegetação é natural, com a presença de Embira (Duguetialanceolata), Aroeira (Schinusterebinthifolius) Embaúba (CecropiapachystachyaTrec) e Samambaia (Aspleniumgastonis) segundo Blum (2008).

\section{Figura 3: Área de Preservação Permanente do assentamento Che Guevara}

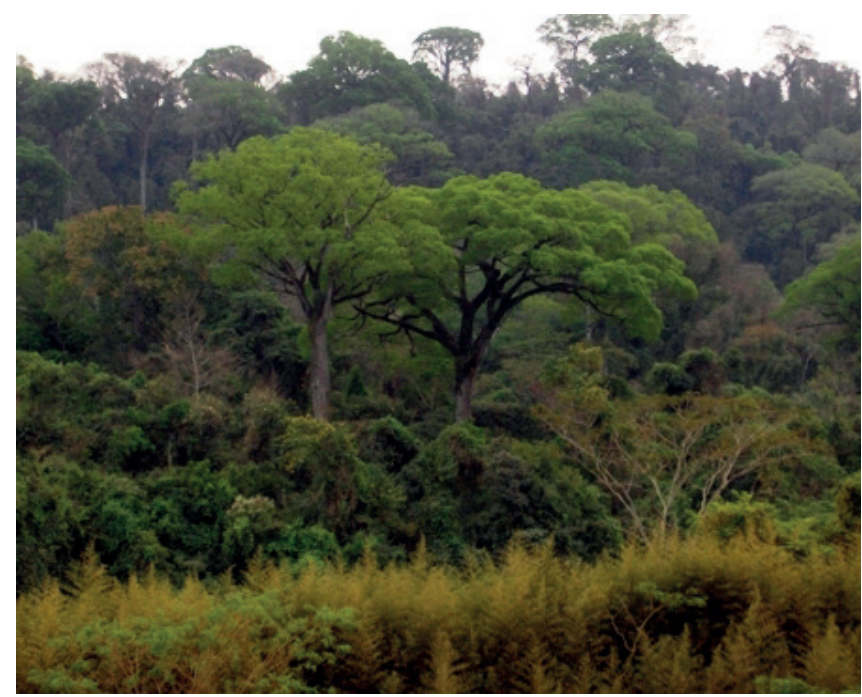

Foto: Neves (2013)

Já em outros locais a APP e/ou Reserva Legal estão alteradas com espécies naturais e exóticas "invasoras", como a leucena (Leucaenaleucocephala).

A não conservação destas reservas florestais é um facilitador de processos erosivos como sulco, ravinas e até voçorocas, ilustrado pela figura 4. A fotografia é de uma fazenda localizada no município de Santa Mônica. 


\section{Figura 4: Feição erosiva acarretado pela descarga de água}

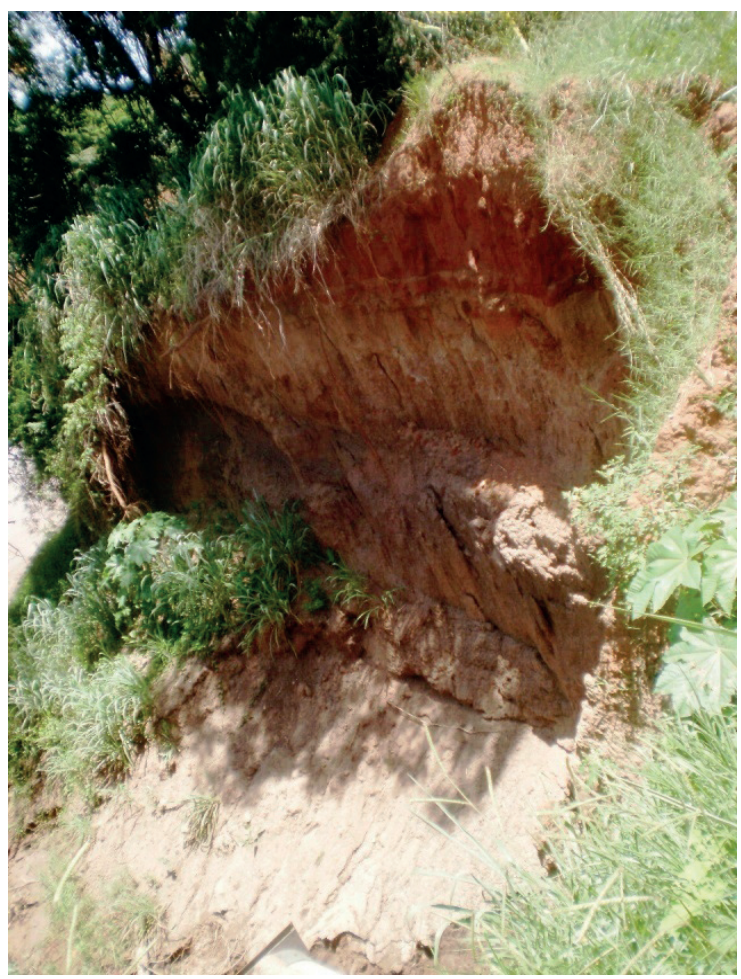

Foto: Neves (2013)

Em relação à área de Reserva Legal nas propriedades, a situação se apresenta quase que idêntica a das APP's, em oitenta e seis $(71,70 \%)$ das propriedades a Reserva Legal está preservada, e não há presença de tal reserva em trinta e quatro $(28,30 \%)$ propriedades analisadas conforme averiguado na área de estudo.

\section{ANÁLISE DA ESTRUTURA FUNDIÁRIA RELACIONADA A DEGRADAÇÃO DA VEGETAÇÃO NAS PRO- PRIEDADES RURAIS ANALISADAS}

$\mathrm{Na}$ análise dos resultados desta pesquisa foi realizado o cruzamento de tabelas dos questionários aplicados, para poder avaliar se a estrutura fundiária interfere na degradação da vegetação.

Relacionando os tipos de estrutura fundiária e a presença de Área de Preservação Permanente nas propriedades analisadas na tabela 2, podemos diagnosticar que quanto ao minifúndio há presença de APP em 98,33\% das propriedades analisadas, e em 85,71\% das pequenas propriedades. A presença de APP nas médias e grandes propriedades diminui significantemente, sendo de 30,43\% nas médias propriedades e de 39,13\% nas grandes propriedades. 
Tabela 2: Relação entre o tamanho e a presença de Área de Preservação Permanente (APP) nas propriedades analisadas

\begin{tabular}{|c|c|c|c|c|c|}
$\begin{array}{c}\text { Estrutura Fundiária } \\
\text { APP }\end{array}$ & Minifúndio & $\begin{array}{c}\text { Pequena } \\
\text { propriedade }\end{array}$ & $\begin{array}{c}\text { Média } \\
\text { propriedade }\end{array}$ & $\begin{array}{c}\text { Grande } \\
\text { propriedade }\end{array}$ & Total \\
\hline SIM & $59(98,33 \%)$ & $12(85,71 \%)$ & $7(30,43 \%)$ & $9(39,13 \%)$ & 87 \\
\hline NÃO & $1(1,77 \%)$ & $2(14,29 \%)$ & $16(69,57 \%)$ & $14(60,87 \%)$ & 33 \\
\hline Total & $\mathbf{6 0 ( 1 0 0 \% )}$ & $\mathbf{1 4 ( 1 0 0 \% )}$ & $\mathbf{2 3}(\mathbf{1 0 0} \%)$ & $\mathbf{2 3}(\mathbf{1 0 0} \%)$ & $\mathbf{1 2 0}$ \\
\hline
\end{tabular}

Fonte: Neves (2013)

Levando-se em consideração a presença de Reserva Legal e o tamanho das propriedades (Tabela 3), foi obtido um mesmo cenário, com o minifúndio e a pequena propriedade apresentando, consecutivamente, 98,33\% e 78,57\% de propriedades com Reserva Legal, e a média e a grande propriedade apresentando a mesma quantidade de propriedades com Reserva Legal do que propriedades com presença de APP.

Tabela 3: Relação entre o tamanho e a presença de Reserva Legal nas propriedades analisadas

\begin{tabular}{c|c|c|c|c|c}
$\begin{array}{c}\text { Estrutura Fundiária } \\
\text { Reserva Legal }\end{array}$ & Minifúndio & $\begin{array}{c}\text { Pequena } \\
\text { propriedade }\end{array}$ & $\begin{array}{c}\text { Média } \\
\text { propriedade }\end{array}$ & $\begin{array}{c}\text { Grande } \\
\text { propriedade }\end{array}$ & Total \\
\hline SIM & $59(98,33 \%)$ & $11(78,57 \%)$ & $7(30,43 \%)$ & $9(39,13 \%)$ & 86 \\
\hline NÃO & $1(1,77 \%)$ & $3(21,43 \%)$ & $16(69,57 \%)$ & $14(60,87 \%)$ & 34 \\
\hline Total & $\mathbf{6 0 ( 1 0 0 \% )}$ & $\mathbf{1 4 ( 1 0 0 \% )}$ & $\mathbf{2 3 ( 1 0 0 \% )}$ & $\mathbf{2 3 ( 1 0 0 \% )}$ & $\mathbf{1 2 0}$ \\
\hline
\end{tabular}

Fonte: Neves (2013)

Com o cruzamento entre os dados do tamanho das propriedades e a presença de Área de Preservação Permanente, e do tamanho da propriedade com a presença de Reserva Legal, vemos quadros semelhantes, nos quais o tamanho da propriedade é determinante na presença dessas áreas.

O minifúndio e a pequena propriedade apresentam os maiores índices de presença de APP's e de Reserva Legal. Isto se deve principalmente ao fato de que os minifúndios e as pequenas propriedades analisadas são majoritariamente propriedades de assentamentos rurais, haja vista pela ocorrência de cinco assentamentos na área de estudo, que são regularmente fiscalizados pelo INCRA, o que torna necessária a conservação destas áreas até para não se perder a titulação da propriedade. 
Já nas médias e grandes propriedades a presença de APP e Reserva Legal é pouco expressiva, estando presente adequadamente com a lei apenas em, respectivamente, 30,43\% e $39,13 \%$ das propriedades analisadas. Este quadro se dá possivelmente, pela não fiscalização adequada da Secretaria do Meio Ambiente nestas cidades, e do Ministério do Meio Ambiente.

\section{CONSIDERAÇÕES FINAIS}

No decorrer desta pesquisa foram discutidos a estrutura fundiária e aspectos do meio ambiente no Brasil, dando ênfase às diferentes estruturas agrícolas (pequena, média, grande propriedade e minifúndio). Houve também a discussão sobre a degradação da vegetação.

Com a análise dos questionários aplicados em 120 propriedades de uma população de 5.865 propriedades foi possível sanar todos os objetivos previstos desta pesquisa, como a realização do levantamento da forma como ocorre a produção em diferentes propriedades agrícolas, sendo ela grande, média, pequena ou minifúndio, e suas relações com a vegetação.

A partir da análise dos dados quantificados no trabalho, deduziu-se que quanto à presença de Área de Preservação Permanente e Reserva Legal, os minifúndios e as pequenas propriedades possuem os melhores números quanto a legalidade destas áreas, com respectivamente 98,33\% e 85,71\% propriedades com presença de APP e, 98,33\%; 78,57\%, no caso da Reserva Legal. Sendo que na média propriedade e na grande propriedade esta ocorrência é muito menor, 30,43\% nas médias propriedades e 39,13\% nas grandes propriedades em ambos os casos.

Porém, os resultados confirmaram que esta legalidade, quanto à presença de APP e de Reserva Legal, não se deve a uma política ambiental, mas sim a uma fiscalização maior do que sofrem as médias e grandes propriedades, por serem assentamentos.

Portanto, a política de criação de assentamento rural pode e deve servir na conservação de áreas florestais além de proporcionar uma distribuição igualitária de terras no Brasil e em especial no Noroeste do Paraná, área de estudo desta pesquisa. 


\section{REFERÊNCIAS}

1. ANDRADE, M. C. Espaço Agrário Brasileiro: velhas formas, novas funções, novas formas velhas funções. GEOUSP - Espaço e Tempo, São Paulo, n. 12, p.11-19, 2002.

2. BARBETTA, P. A. Estatística Aplicada às Ciências Sociais. $2^{\text {a }}$ ed. Florianópolis: Ed. da UFSC, 1998. 284p.

3. BERGAMASCO, S. M.; NORDER, L. A. C. O que são assentamentos rurais. São Paulo: Brasiliense, 1996. 88p. (Col. Primeiros Passos, 301)

4. BIGARELLA, J. J.; MAZUCHOWSKI, J.Z. Visão integrada da problemática da erosão. Curitiba, Associação de Defesa e Ducação Ambiental/ Associação Brasileira de Geologia e Engenharia, p. 187-189, 1985.

5. BLUM, C.T. Lista Preliminar de Espécies Vegetais da Floresta Estacional Semidecidual no Paraná - versão 2008. FLORAPARANÁ, Sociedade Chauá. Disponível em <www.chaua.org. br/fsdrp >. Acesso em: jan. 2013.

6. BRASIL. Lei n 4.504, de 30 de novembro de 1964 - Dispõe sobre o Estatuto da Terra, e dá outras definições. Disponível em: <http://www.planalto.gov.br/ccivil_03/leis/L4504.htm>. Acesso em: 14 mai. 2012.

7. BRASIL. Decreto n. 4.771, de 15 de setembro de 1965 - Institui o novo código florestal. Disponível em: <http://www.planalto.gov.br/ccivil_03/leis/L4771.htm>. Acesso em 14 mai. 2012.

8. BRASIL. Decreto n. 84.685, de 6 de maio de $\mathbf{1 9 8 0}$ - Estabelece o Módulo Fiscal de cada município. Disponível em: <http://www6.senado.gov.br/legislacao/ListaTextoIntegral. action?id=102455\&norma=125907>. Acesso em: 14 mai. 2012.

9. BRASIL. Constituição (1988). Constituição da República Federativa do Brasil: promulgada em 5 de outubro de 1988. 4. ed. São Paulo: Saraiva, 1990. 168p.

10. BRASIL. Lei no $\mathbf{8 . 6 2 9}$, de 25 de fevereiro de 1993 - Dispõe sobre a reforma agrária. Disponível em: <http://www.planalto.gov.br/ccivil_03/leis/18629.htm>. Acesso em: 14 mai. 2012.

11. CAMPOS, J. B. A pecuária e a degradação social e ambiental do noroeste do Paraná. Caderno Biodiversidade, v. 2, n. 1, p. 1-3, 1999.

12. CARVAlHO, J. B. de. A verdadeira História das Capitanias Hereditárias. São Paulo: Ed. do Autor, 2008. 227p.

13. DERPESCH, R.; ROTH, C. H.; SIDÍRAS, N.; KÖPKE, U. Controle de erosão no Paraná, Brasil: sistemas de cobertura do solo, plantio direto e preparo conservacionista do solo. Tradução de Irene Popper. Eschborn-Alemanha/Paraná: Deutsche GesellschftfürTechnischeZusammenarbeit (GTZ) GmbH/Fundação Instituto Agronômico do Paraná (IAPAR), 1991. 272p.

14. DESTEFANI, E. V. Regime hidrológico do rio Ivaí-PR. 2005. Dissertação (Mestrado) Programa de Pós-Graduação em Geografia - Universidade Estadual de Maringá, Maringá, 2005. 94p. 
15. FREITAS, N. Artigos - o Conhecimento. Disponível em: <http://www.newton.freitas.nom. br/artigos.asp?cod=4>. Acesso em: dez. 2012.

16. GASPARETTO, N. V. L.; SOUZA, M. L. Contexto geológico-geotécnico da Formação Caiuá no Terceiro Planalto Paranaense - PR. In: ENCONTRO GEOTÉCNICO DO TERCEIRO PLANALTO PARANAENSE, Maringá, v.1, p.53-65. 2003.

17. GRAZIANO DA SILVA, J. (Coord.). Estrutura agrária e produção de subsistência na agricultura brasileira. 2.ed. São Paulo: Hucitec, 1980. 240p.

18. HARACENKO, A. A. S. Querência do Norte: uma experiência de colonização e reforma agrária no Noroeste paranaense. Maringá: Editora Massoni, 2002. 218p.

19. IAPAR - INSTITUTO AGRONÔMICO DO PARANÁ. Cartas Climáticas básicas do estado do Paraná. Londrina: IAPAR, 1994, 1 atlas, 38p., il., $30 \mathrm{~cm}$.

20. IBGE - INSTITUTO BRASILEIRO DE GEOGRAFIA E ESTATÍSTICA. Manual Técnico da Vegetação Brasileira. Série Manuais Técnicos em Geociências - n. 1. Rio de Janeiro: IBGE, 1992. 92p.

21. IBGE - Instituto Brasileiro de Geografia e Estatística. Área territorial oficial. Resolução da Presidência do IBGE de nº 5. 10 out. 2002. Disponível em: <http://www.ibge.gov.br/home/ geociencias/cartografia/default_territ_area.shtm>. Acesso em: 27 nov. 2012.

22. IPARDES - INSTITUTO PARANAENSE DE DESENVOLVIMENTO ECONÔMICO E SOCIAL. Relação dos municípios do Estado ordenados segundo as Mesorregiões e as microrregiões geográficas do IBGE - PARANÁ - 2012. Disponível em: <http://www.ipardes.gov.br/pdf/mapas/ base_fisica/relacao_mun_micros_mesos_parana.pdf >. Acesso em: 17 jul. 2012a.

23. IPARDES - INSTITUTO PARANAENSE DE DESENVOLVIMENTO ECONÔMICO E SOCIAL. Perfil da Região Geográfica do Noroeste Paranaense. 2012. Disponível em: <http:// www.ipardes.gov.br/perfil_regioes/MontaPerfilRegiao.php?Municipio $=100 \& b t O k=o k>$. Acesso em: 17 jul. 2012b.

24. IPARDES - INSTITUTO PARANAENSE DE DESENVOLVIMENTO ECONÔMICO E SOCIAL. Perfil da Microrregião Geográfica de Paranavaí. 2012. Disponível em: <http://www. ipardes.gov.br/perfil_regioes/MontaPerfilRegiao.php?Municipio $=413 \& b t O k=o k>$. Acesso em: 17 jul. 2012c.

25. IPARDES - INSTITUTO PARANAENSE DE DESENVOLVIMENTO ECONÔMICO E SOCIAL. Perfil da Microrregião Geográfica de Umuarama. 2012. Disponível em: http://www. ipardes.gov.br/perfil_regioes/MontaPerfilRegiao.php?Municipio $=414 \& b t O k=o k>$. Acesso em: 17 jul. 2012d.

26. KÖPPEN, W. Climatologia: com um Estúdio de los Climas de La Tierra. México: Fondo de Cultura Econômica, 1948. 466p.

27. MAACK, R. Geografia física do estado do Paraná. $2^{\text {a }}$ ed. Rio de Janeiro: Olympio/ Curitiba: Secretaria da Cultura e do Esporte do governo do estado do Paraná, 1981. 350p.

28. MARQUES, B. F. Direito agrário brasileiro. 9a ed. São Paulo: Editora Atlas, 2011. 260p. 
29. MARTINE, G.; BESKOW, P. R. O modelo, os instrumentos e as transformações na estrutura de produção agrícola. In: MARTINE, G., GARCIA, R. C. (Orgs.). Os impactos sociais da modernização agrícola. São Paulo: Caetés, 1987. p. 19-39

30. MORO, A. D. Substituição de culturas, modernização agrícola e organização do espaço rural, no norte do Paraná. Tese (Doutorado em Geociência) - Departamento de Geografia Universidade Estadual Paulista, Rio Claro, 1991. 353p.

31. NEVES, P. D. M. A estrutura fundiária e suas implicações ambientais em municípios do baixo curso do rio Ivaí-PR, no período de 2011 a 2012. 2013. Dissertação (Mestrado) - Programa de Pós-Graduação em Geografia - Universidade Estadual de Maringá, Maringá, 2013. 98p.

32. TRICART, J. Ecodinâmica. Rio de Janeiro: Fundação Instituto Brasileiro de Geografia e Estatística - IBGE, 1977. 97 p.

33. TROPPMAIR, H. Perfil fitoecológico do estado do Paraná. Boletim de Geografia (UEM), Maringá, v. 8, n.1, p. 67-80, 1994. 